\title{
Exigências em proteína bruta para codornas de corte EV1 em crescimento
}

[Crude protein requirements for EVI meat type quail during the growing period]

\author{
G.S.S. Corrêa ${ }^{1,5}$, M.A. Silva ${ }^{1,5}$, A.B. Corrêa ${ }^{2,5}$, D.O. Fontes ${ }^{1}$, G.G. Santos ${ }^{1,5}$, \\ R.A. Torres ${ }^{3,5}$, N.J.L. Dionello ${ }^{4}$, L.S. Freitas ${ }^{2,5}$, A.B. Fridrich ${ }^{2,5}$ \\ ${ }^{1}$ Escola de Veterinária - UFMG \\ Caixa Postal 567 \\ 30123-970 - Belo Horizonte, MG \\ ${ }^{2}$ Aluno de pós-graduação - EV-UFMG - Belo Horizonte, MG \\ ${ }^{3}$ Departamento de Zootecnia - UFV - Viçosa MG \\ ${ }^{4}$ Departamento de Zootecnia - FAEM-UFPel - Pelotas, RS \\ ${ }^{5}$ Bolsista do $\mathrm{CNPq}$ \\ RESUMO
}

\begin{abstract}
Estudou-se a exigência de proteína bruta para a linha EV1 de codornas de corte na fase de crescimento utilizando-se 288 aves, de ambos os sexos, em delineamento experimental inteiramente ao acaso, cujos tratamentos foram dietas com seis níveis proteína bruta, 23, 25, 27, 29, 31 e 33\%, e quatro repetições de 12 codornas por unidade experimental. Nos períodos de estudo - inicial (do nascimento ao $21^{\circ}$ dia) e total (do nascimento ao $42^{\circ}$ dia de idade) - foram registrados o peso corporal (g), o ganho de peso $(\mathrm{g})$, o consumo de ração $(\mathrm{g})$ e a conversão alimentar ( $\mathrm{g}$ de ração/g de peso). No período inicial houve efeito quadrático do nível de proteína da dieta sobre peso corporal, ganho de peso e consumo alimentar, com máximo desempenho nos níveis de 30,$2 ; 30,1 ;$ e $30,8 \%$, respectivamente. Efeito quadrático significativo foi observado no peso no $42^{\circ}$ dia de idade, com pico máximo em $30,2 \%$ de proteína bruta. Do nascimento ao $42^{\circ}$ dia de idade, observou-se efeito quadrático do nível de proteína bruta sobre o ganho de peso e o consumo alimentar, com ponto de máximo para ganho de peso em 29,5 e maior consumo em 32,6\% de PB. Houve efeito linear significativo do nível protéico sobre a conversão alimentar. A exigência de proteína bruta para o máximo ganho de peso de codornas de corte em crescimento do nascimento ao $21^{\circ}$ dia de idade foi estimada em $30,1 \%$ e do nascimento ao $42^{\circ}$ dia, em $29,4 \%$ da dieta.
\end{abstract}

Palavras-chave: codorna, exigência nutricional, ganho de peso, consumo alimentar, conversão alimentar, proteína bruta

\begin{abstract}
Crude protein requirements for EV1 meat type quails were estimated using 288 quails of both sexes in a completely randomized experimental design with six crude protein levels $(23,25,27,29,31$ and 32\%) and four replicates of 12 quails per experimental unit. The following traits were recorded in each experimental period (from hatch to 21 days and from hatch to 42 days of age): body weight (g), weight gain (g), feed intake (g), and feed:weight gain ratio. From hatch to 21 days of age quadratic effects of crude protein levels on live body weight, weight gain and feed intake were observed and maximum performances were estimated for quails fed 30.2; 30.1; and 30.8\% crude protein diets, respectively. Quadratic effect of protein level on body weight at 42 days of age was significant and quails fed $30.2 \%$ crude protein diets showed maximum performance. Quails fed 29.5 and $32.6 \%$ crude protein diets from hatch to 42 days showed maximum weight gain and feed intake while feed:weight gain ratio was negative and linearly related to crude protein level of diet. Crude protein requirement for weight gain (male and female), from hatch to 21 days of age is estimated in $30.1 \%$ and from hatch to 42 days of age in $29.5 \%$.
\end{abstract}

Keywords: quail, nutritional requirement, weight gain, feed consumption, feed :weight gain ratio, crude protein

Recebido em 21 de dezembro de 2006

Aceito em 24 de outubro de 2007

E-mail: gerusacorrea@hotmail.com 


\section{INTRODUÇÃO}

A determinação das exigências nutricionais é de grande importância para todas as espécies avícolas, uma vez que o fornecimento de níveis adequados dos nutrientes é o principal fator que determina se as aves vão expressar todo o seu potencial genético.

As codornas de corte apresentam maiores pesos e taxas de crescimento que as codornas de postura (Corrêa et al., 2007b).

Entretanto, a maioria das informações disponíveis sobre os requisitos nutricionais de codornas ainda é obtida de literatura estrangeira, em condições totalmente diversas das vigentes no Brasil (Rajini e Narahari, 1998; Shrivastav e Panda, 1999; Oliveira et al., 2000), além de se referirem às exigências de codornas japonesas, as quais apresentam maior aptidão para postura (Corrêa et al., 2007a), o que pode determinar exigências nutricionais diferentes.

Dentre os diversos nutrientes de uma dieta destacam-se as fontes protéicas, pois são os componentes de maior participação no custo das dietas e, conseqüentemente, de maior importância nas formulações de dietas comerciais que devem suprir as necessidades das codornas, sem onerar o custo de produção.

Alguns autores têm observado maiores pesos de codornas japonesas alimentadas com dietas com $30 \%$ de proteína bruta, do nascimento ao $35^{\circ}$ dia de idade (Kirkpinar e Oguz, 1995). Vohra e Roudybush (1971) não observaram diferença no ganho de peso de codornas alimentadas com dietas com níveis de proteína bruta que variaram de 20 a 35\%. Marks (1978) observou que o ganho de peso de codornas japonesas alimentadas com dietas com $20 \%$ de proteína bruta, da segunda à sexta semana de idade, foi $96 \%$ menor que o de codornas alimentadas com $28 \%$ de proteína bruta.

Lesson e Summers (1997) recomendaram, para codornas selecionadas para produção de carne, dietas com $28 \%$ de proteína até a sexta semana e
$18 \%$ até o abate. Corrêa et al. (2005) estabeleceramm $28 \%$ de PB para codornas de corte em crescimento e Corrêa et al. (2007b) estimaram as exigências de proteína bruta para codornas de corte em $27 \%$ do sétimo ao $21^{\circ}$ dia de idade.

Assim, este trabalho teve o objetivo de estudar o efeito de diferentes níveis de proteína bruta da dieta sobre o desempenho de codornas de corte do grupo genético EV1, no período de crescimento.

\section{MATERIAL E MÉTODOS}

Foram utilizadas 288 codornas de corte EV1, de ambos os sexos, com um dia de idade, peso médio inicial de $8,0 \mathrm{~g}$, distribuídas em delineamento inteiramente ao acaso, com seis níveis de proteína bruta, 23, 25, 27, 29, 31 e $33 \%$, e quatro repetições de 12 codornas por unidade experimental.

As dietas experimentais foram formuladas com base na composição dos ingredientes, apresentadas por Rostagno et al. (2000), e as exigências nutricionais das codornas, de acordo com o NRC (Nutrient...,1994), exceto para os níveis de $\mathrm{PB}$.

O programa de luz utilizado foi contínuo (24 horas de luz natural + artificial) durante $o$ período experimental.

O desempenho foi avaliado pelo ganho de peso $(\mathrm{g})$, peso ao final de cada período $(\mathrm{g})$, consumo alimentar (g/ave) e conversão alimentar ( $g$ de dieta/g de peso) no período inicial (do nascimento ao $21 .^{\text {a }}$ dia de idade) e total (do nascimento ao $42 .^{\circ}$ dia de idade).

A análise dos dados foi realizada por meio do programa SAEG (Sistema..., 2004). As exigências de proteína bruta foram obtidas regredindo-se as variáveis respostas em relação aos níveis significativos de proteína bruta em seus componentes lineares e quadráticos, para escolha do modelo de regressão que melhor descrevesse as observações. 


\section{Corrêa et al.}

Tabela 1. Composição percentual e calculada das dietas experimentais usadas para codornas em crescimento

\begin{tabular}{|c|c|c|c|c|c|c|}
\hline & \multicolumn{6}{|c|}{ Proteína Bruta (\%) } \\
\hline Ingrediente (\%) & 23 & 25 & 27 & 29 & 31 & 33 \\
\hline Milho & 57,94 & 51,17 & 44,93 & 38,40 & 31,88 & 25,36 \\
\hline Farelo de soja & 36,78 & 42,48 & 47,78 & 53,30 & 58,81 & 64,32 \\
\hline Farinha de carne e ossos & 2,60 & 2,60 & 2,60 & 2,60 & 2,60 & 2,60 \\
\hline Óleo de soja & 0,33 & 1,46 & 2,45 & 3,52 & 4,58 & 5,65 \\
\hline Calcário & 0,86 & 0,84 & 0,82 & 0,79 & 0,77 & 0,75 \\
\hline Fosfato bicálcico & 0,16 & 0,13 & 0,11 & 0,08 & 0,05 & 0,02 \\
\hline Suplem. min. e vit. ${ }^{1}$ & 0,50 & 0,50 & 0,50 & 0,50 & 0,50 & 0,50 \\
\hline Sal comum & 0,23 & 0,22 & 0,22 & 0,21 & 0,21 & 0,20 \\
\hline DL- metionina & 0,10 & 0,15 & 0,19 & 0,23 & 0,28 & 0,32 \\
\hline L-treonina & 0,06 & 0,11 & 0,13 & 0,17 & 0,20 & 0,23 \\
\hline Inerte & 0,44 & 0,34 & 0,28 & 0,20 & 0,12 & 0,05 \\
\hline Total & 100,00 & 100,00 & 100,00 & 100,00 & 100,00 & 100,00 \\
\hline \multicolumn{7}{|l|}{ Composição calculada } \\
\hline Proteína bruta $(\%)$ & 23,00 & 25,00 & 27,00 & 29,00 & 31,00 & 33,00 \\
\hline Energia metab. (kcal/kg) & 2900 & 2900 & 2900 & 2900 & 2900 & 2900 \\
\hline Cálcio (\%) & 0,80 & 0,80 & 0,80 & 0,80 & 0,80 & 0,80 \\
\hline Fósforo disponível (\%) & 0,30 & 0,30 & 0,30 & 0,30 & 0,30 & 0,30 \\
\hline Fósforo total $(\%)$ & 0,54 & 0,55 & 0,56 & 0,58 & 0,59 & 0,60 \\
\hline Gordura $(\%)$ & 3,12 & 4,10 & 4,93 & 5,84 & 6,74 & 7,65 \\
\hline Lisina digestível (\%) & 1,10 & 1,23 & 1,35 & 1,47 & 1,60 & 1,73 \\
\hline Lisina total $(\%)$ & 1,23 & 1,37 & 1,50 & 1,64 & 1,77 & 1,91 \\
\hline Met.+cist. total (\%) & 0,81 & 0,76 & 0,99 & 1,08 & 1,17 & 1,26 \\
\hline Metionina digestível(\%) & 0,42 & 0,35 & 0,55 & 0,62 & 0,69 & 0,75 \\
\hline Metionina total (\%) & 0,55 & 0,48 & 0,69 & 0,76 & 0,83 & 0,90 \\
\hline Sódio $(\%)$ & 0,15 & 0,15 & 0,15 & 0,15 & 0,15 & 0,15 \\
\hline Treonina digestível (\%) & 0,82 & 0,93 & 1,03 & 0,12 & 1,22 & 1,31 \\
\hline Treonina total $(\%)$ & 0,95 & 1,07 & 1,17 & 1,28 & 1,38 & 1,49 \\
\hline Triptofano digestível (\%) & 0,25 & 0,28 & 0,31 & 0,34 & 0,37 & 0,40 \\
\hline Triptofano total $(\%)$ & 0,28 & 0,31 & 0,34 & 0,38 & 0,41 & 0,44 \\
\hline
\end{tabular}

${ }^{1}$ Composição por quilo: vit.A: $2.000 .000 \mathrm{UI}$; vit $\mathrm{D}_{3}: 375.000 \mathrm{UI}$; vit.E: $3.750 \mathrm{mg}$; vit. $\mathrm{K}_{3}: 500 \mathrm{mg}$; vit.B $\mathrm{B}_{1}: 250 \mathrm{mg}$; vit. $\mathrm{B}_{2}$ : 750mg; vit. $\mathrm{B}_{6}: 500 \mathrm{mg}$; vit. $\mathrm{B}_{12}: 3.750 \mathrm{mcg}$; niacina: $6250 \mathrm{mg}$; ac. Pantotênico: $2500 \mathrm{mg}$; biotina: 10mg; ac.fólico: 125mg; colina: $75.000 \mathrm{mg}$; selênio: $45 \mathrm{mg}$; iodo: $175 \mathrm{mg}$; ferro: $12.525 \mathrm{mg}$; cobre: $2500 \mathrm{mg}$; manganês: $19.500 \mathrm{mg}$; zinco: $13.750 \mathrm{mg}$; avilamicina: $15.000 \mathrm{mg}$; narasin: $12.250 \mathrm{mg}$; BHT: $500 \mathrm{mg}$; vit.C: $12.500 \mathrm{mg}$.

\section{RESULTADOS E DISCUSSÃO}

Do nascimento ao $21^{\circ}$ dia de idade houve efeito quadrático do nível de proteína da dieta sobre peso corporal, ganho de peso e consumo de ração (Tab. 2 e Fig. 1, 2 e 3), com máximo desempenho para codornas alimentadas com dietas contendo 30,2; 30,1 e $30,8 \%$, de proteína bruta, respectivamente. Assim, houve aumento do peso e do ganho de peso à medida que se aumentou o consumo de proteína até o ponto em que se estabeleceu o limite fisiológico para a expressão dessas características.

Estes resultados ressaltam, à semelhança do que ocorre em frangos de corte, que o peso e ganho de peso em codornas de corte são limitados quer pela quantidade de aminoácidos essenciais, em dietas com baixos níveis de proteína quer pela eficiência de utilização dos aminoácidos, em dietas com níveis protéicos acima da exigência. Assim, o nível de $24 \%$ de proteína bruta, preconizado pelo NRC (Nutrient...,1994) para codornas de postura em crescimento não atende as exigências de ganho de peso das codornas de corte porque elas têm maiores taxas de crescimento e peso corporal no $21^{\circ}$ dia de idade que as codornas japonesas, para as quais o NRC (Nutrient..., 1994) descreve as exigências, conforme Corrêa et al. (2006).

Corrêa et al. (2007a) observaram maior ganho de peso do sétimo ao $15^{\circ}$ dia de idade para codornas 
de corte alimentadas com dietas com $25,7 \%$ de proteína, e maior ganho de peso do $16^{\circ}$ ao $21^{\circ}$ dia de idade, quando alimentadas com $27,9 \%$ de proteína bruta. Oliveira et al. (2002), ao utilizarem dietas com níveis de 18 a $26 \%$ de proteína bruta, para codornas japonesas, observaram efeito linear crescente no ganho de peso do quinto ao $16 .^{\circ}$ e do $16 .^{\circ}$ ao $27 .^{\circ}$ dia de idade, em função do nível protéico da dieta. Lee et al. (1977), ao trabalharem com codornas japonesas em crescimento, sugeriram o nível inicial de 28\%, Sakurai (1979) o de 32,2\%, Hyánková et al. (1997) o de $26 \%$ do nascimento ao $21^{\circ}$ dia de idade. Lima Neto et al. (2005) sugeriram o nível $27 \%$ de proteína bruta para codornas de corte, do sétimo ao $21^{\circ}$ dia de idade.

Tabela 2. Peso ao $21^{\circ}$ dia, ganho de peso, consumo de ração e conversão alimentar das codornas do nascimento ao $21^{\circ}$ dia de idade, segundo o nível protéico

\begin{tabular}{ccccc}
$\begin{array}{c}\text { Nível de PB } \\
(\%)\end{array}$ & $\begin{array}{c}\text { Peso ao } 21^{\circ} \text { dia } \\
(\mathrm{g})\end{array}$ & $\begin{array}{c}\text { Ganho de peso } \\
(\mathrm{g})\end{array}$ & $\begin{array}{c}\text { Consumo de } \\
\text { ração } \\
(\mathrm{g})\end{array}$ & $\begin{array}{c}\text { Conversão alimentar } \\
(\mathrm{g} / \mathrm{g})\end{array}$ \\
\hline 23 & 99,69 & 91,60 & 203,75 & 2,23 \\
25 & 113,94 & 105,82 & 234,29 & 2,22 \\
27 & 137,17 & 129,02 & 268,37 & 2,08 \\
29 & 142,13 & 134,05 & 278,08 & 2,07 \\
31 & 136,51 & 128,43 & 290,14 & 2,26 \\
33 & 135,72 & 127,70 & 271,11 & 2,13 \\
\hline CV & 4,38 & 4,68 & 2,64 & ns \\
\hline Significância & $*$ & $*$ & $*$ & Nível de melhor \\
\hline & & Equação de regressão & 30,2 \\
\hline Peso ao 21 ${ }^{\circ}$ dia & $\hat{Y}_{i}=-630,64+51,25 X_{i}-0,85 X_{i}^{2}\left(\mathrm{R}^{2}=0,95\right)$ & 30,1 \\
\hline Ganho de peso & $\hat{Y}_{i}=-637,15+51,13 X_{i}-0,85 X_{i}^{2}\left(\mathrm{R}^{2}=0,95\right)$ & 30,8 \\
\hline \multirow{2}{*}{ Consumo alimentar } & $\hat{Y}_{i}=-1106,19+92,32 X_{i}-1,50 X_{i}^{2}\left(\mathrm{R}^{2}=0,98\right)$ & \\
\hline
\end{tabular}

$*=\mathrm{P}<0,05 ; \mathrm{ns}=\mathrm{P}>0,05$ pelo teste Fischer

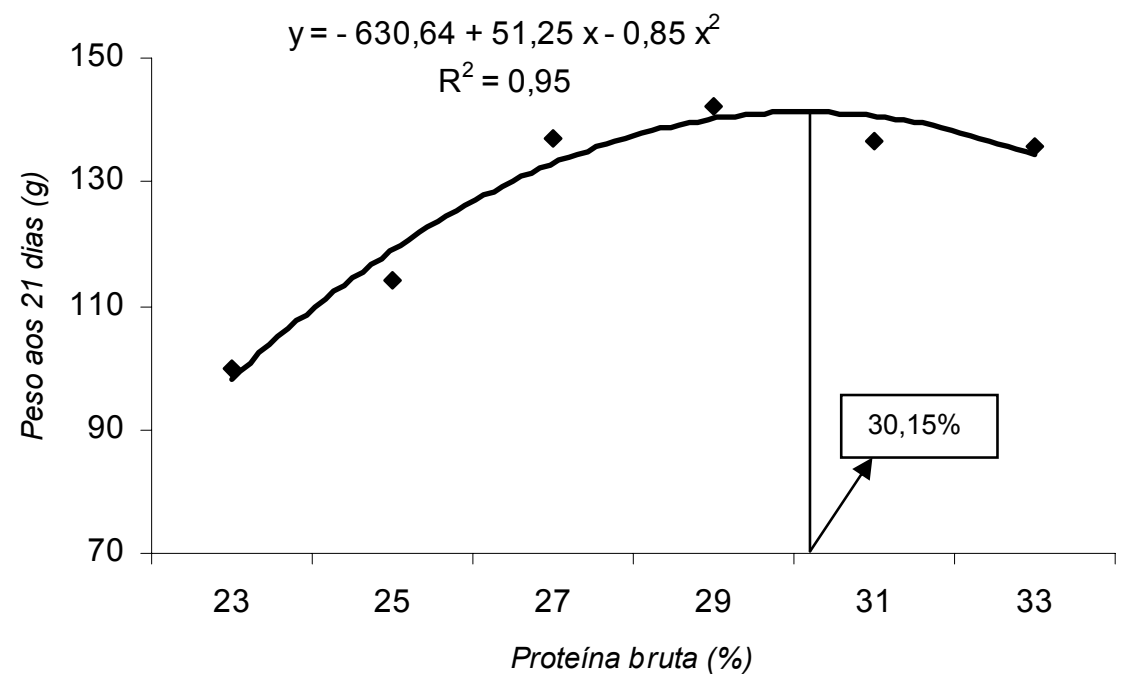

Figura 1. Regressão do peso no $21^{\circ}$ dia de idade de codornas de corte EV1 em relação ao nível de proteína bruta da dieta. 


\section{Corrêa et al.}

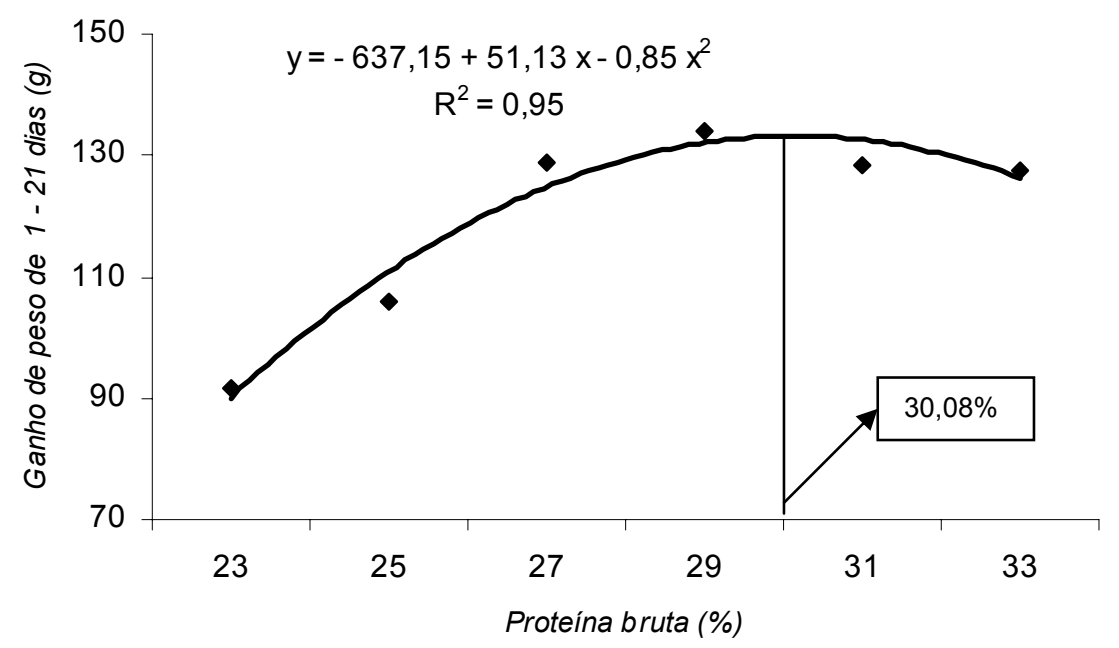

Figura 2. Regressão do ganho de peso do nascimento ao $21^{\circ}$ dia de idade de codornas de corte EV1 em relação ao nível de proteína bruta da dieta.

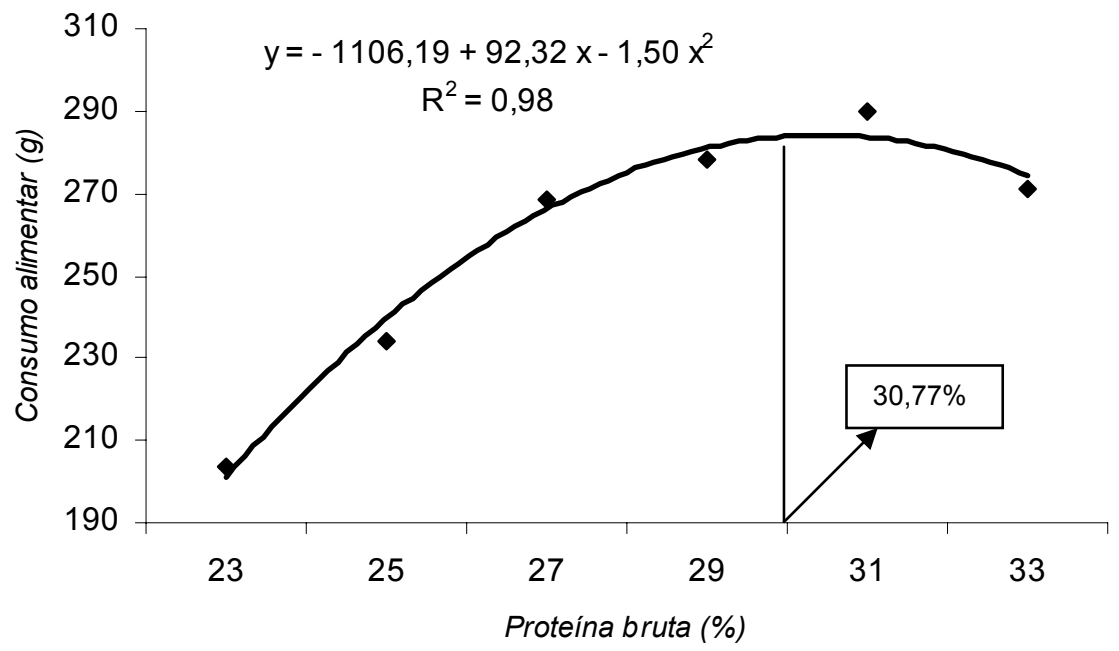

Figura 3. Regressão do consumo alimentar do nascimento ao $21^{\circ}$ dia de idade de codornas de corte EV1 em relação ao nível de proteína bruta da dieta.

A diferença observada nos resultados deste trabalho (do nascimento ao $21 .^{\circ}$ dia de idade) com os de Lima Neto et al. (2005) e de Corrêa et al. (2007a), também em codornas de corte, pode ser atribuída ao fato de que esses autores estabeleceram as exigências para codornas de corte do sétimo ao $21^{\circ}$ dia de idade. Sabe-se, contudo, que do nascimento ao sétimo dia de idade as codornas são bastante exigentes em proteína, pois nascem com oito gramas $\mathrm{e}$ apresentam já no sétimo dia de idade peso médio de 32 gramas, o que eqüivale a um aumento de quatro vezes o seu peso inicial. Portanto, esperase exigência em proteína bruta mais alta que os valores encontrados pelos citados autores para atender à maior demanda causada por essa alta 
taxa inicial de crescimento do nascimento ao sétimo dia de idade.

A conversão alimentar durante a fase inicial não foi influenciada pelos níveis de proteína bruta da dieta. Estes resultados foram semelhantes aos de Lepore e Marks (1971) que observaram efeito do nível protéico sobre o consumo alimentar, mas não sobre a conversão alimentar. Portanto, os resultados indicam que a redução e/ou excesso da proteína da dieta de codornas de corte na fase inicial (do nascimento ao $21^{\circ}$ dia), pode influir de forma negativa no desempenho das codornas, por causa da limitação ou da menor eficiência de utilização de aminoácidos essenciais.

Houve efeito quadrático significativo dos níveis de proteína bruta da dieta sobre o peso no $42^{\circ}$ dia de idade (Tab. 3 e Fig. 4), com pico máximo de peso em $30,2 \%$ de proteína bruta.

Tabela 3. Peso final, ganho de peso, consumo de ração e conversão alimentar das codornas de corte do nascimento ao $42^{\circ}$ dia de idade segundo o nível de proteína

\begin{tabular}{|c|c|c|c|c|}
\hline $\begin{array}{c}\text { Nível de PB } \\
(\%)\end{array}$ & $\begin{array}{l}\text { Peso final } \\
(\mathrm{g})\end{array}$ & Ganho de peso(g) & $\begin{array}{l}\text { Consumo de ração } \\
(\mathrm{g})\end{array}$ & $\begin{array}{c}\text { Conversão alimentar } \\
(\mathrm{g} / \mathrm{g})\end{array}$ \\
\hline 23 & 242,72 & 234,69 & 759,15 & 3,23 \\
\hline 25 & 251,25 & 246,10 & 785,32 & 3,19 \\
\hline 27 & 272,25 & 267,05 & 829,30 & 3,11 \\
\hline 29 & 265,19 & 263,30 & 853,38 & 3,25 \\
\hline 31 & 263,91 & 259,09 & 881,76 & 3,40 \\
\hline 33 & 267,44 & 257,71 & 861,45 & 3,35 \\
\hline $\mathrm{CV}$ & 3,60 & 3,97 & 2,32 & 3,48 \\
\hline Significância & $*$ & $*$ & $*$ & $*$ \\
\hline & \multicolumn{3}{|c|}{ Equação de Regressão } & $\begin{array}{l}\text { Nível de melhor } \\
\text { desempenho }\end{array}$ \\
\hline Peso aos 42 dias & \multicolumn{3}{|c|}{$\hat{Y}_{i}=-194,72+30,73 X_{i}-0,509 X_{i}^{2}\left(\mathrm{R}^{2}=0,80\right)$} & 30,2 \\
\hline Ganho de peso & \multicolumn{3}{|c|}{$\hat{Y}_{i}=-372,97+43,30 X_{i}-0,735 X_{i}^{2} \quad\left(\mathrm{R}^{2}=0,89\right)$} & 29,5 \\
\hline Consumo alimentar & \multicolumn{3}{|c|}{$\hat{Y}_{i}=-517,93+85,479 X_{i}-1,31 X_{i}^{2}\left(\mathrm{R}^{2}=0,96\right)$} & 32,6 \\
\hline Conversão alimentar & \multicolumn{3}{|c|}{$\hat{Y}_{i}=2,72+0,019 X_{i}\left(\mathrm{R}^{2}=0,44\right)$} & 23,0 \\
\hline
\end{tabular}

$*=\mathrm{P}<0,05$ e $\mathrm{ns}=\mathrm{P}>0,05$, pelo teste Fisher.

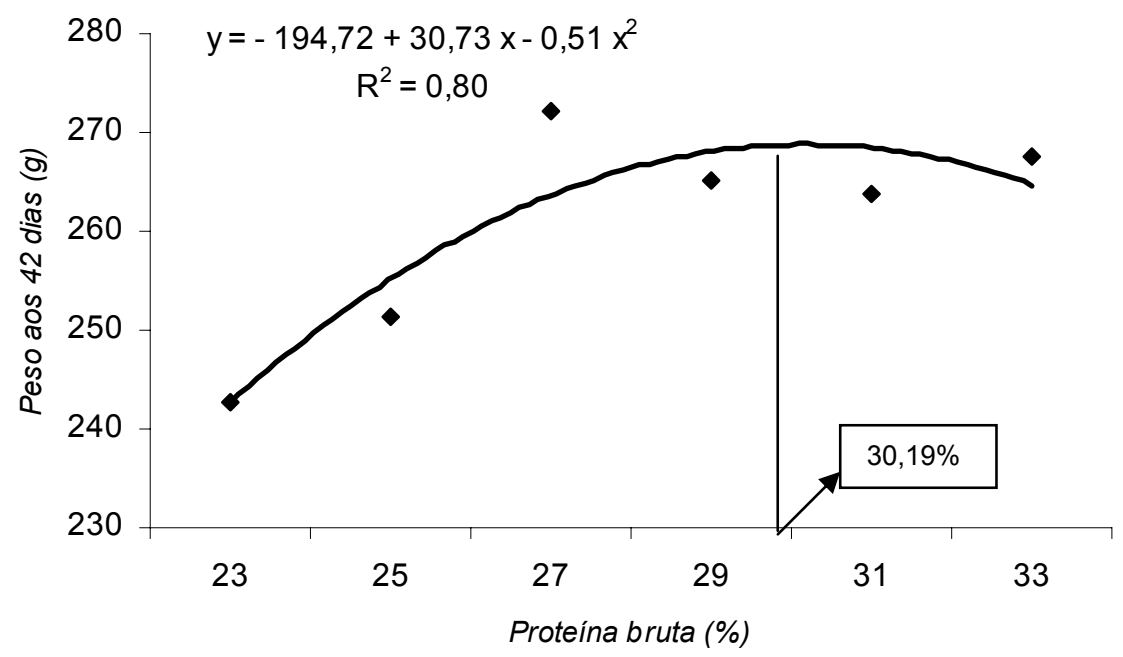

Figura 4. Regressão do peso no $42^{\circ}$ dia de idade de codornas de corte EV1 em relação ao nível de proteína bruta da dieta. 
Lepore e Marks (1971) e Marks (1993) obtiveram melhores pesos na quarta e sexta semanas em codornas de corte de ambos os sexos, alimentadas com níveis de proteína bruta entre 24 e 27\%, enquanto que Murakami (1991) não observou diferenças significativas no peso médio de codornas japonesas, no $42^{\circ}$ dia de idade, alimentadas com dietas que variaram de 20 a $26 \%$ de proteína bruta.

O peso médio das codornas no $42 .^{\circ}$ dia de idade registrado neste experimento foi $265 \mathrm{~g}$, ou seja, acima de $250 \mathrm{~g}$ observado por Corrêa et al. (2006), e bem acima de $130 \mathrm{~g}$ obtido para codornas japonesas no $49 .^{\circ}$ dia de idade por
Oliveira et al., (2002). Espera-se maior exigência de codornas de corte comparada às de postura porque aquelas apresentam maior capacidade de deposição de proteína corporal, decorrente de diferenças anatômicas, histológicas e de tamanho e comprimento de trato gastrintestinal (Oliveira et al., 2007).

O nível protéico da dieta influenciou de forma quadrática o peso e o consumo alimentar (Fig. 5, 6 e Tab. 3), com picos de máximo desempenho para codornas alimentadas com $29,5 \%$ e $32,6 \%$ de PB, no período total de criação (do nascimento ao $42^{\circ}$ dia de idade).

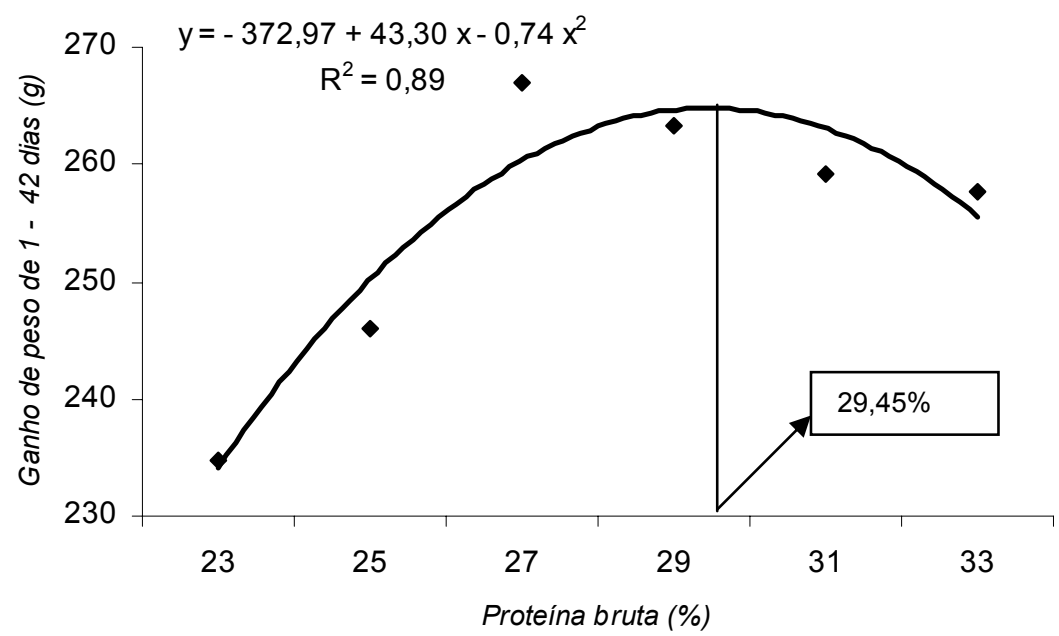

Figura 5. Regressão do ganho de peso do nascimento ao $42^{\circ}$ dia de idade de codornas de corte EV1 em relação ao nível de proteína bruta da dieta.

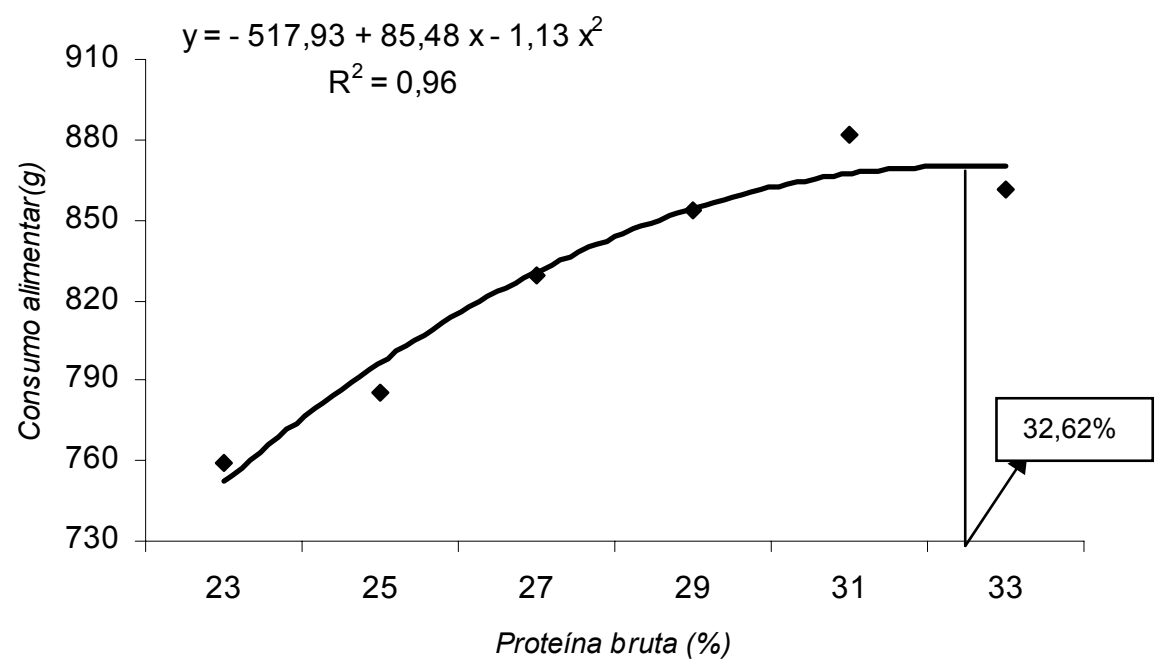

Figura 6. Regressão do consumo alimentar do nascimento ao $42^{\circ}$ dia de idade de codornas de corte EV1 em relação ao nível de proteína bruta da dieta. 
Resultados semelhantes foram encontrados por Marks (1978) que observou maior ganho de peso em codornas japonesas alimentadas com dietas com $28 \%$ em comparação às alimentadas com $20 \%$ de $\mathrm{PB}$, da segunda à sexta semana de idade. Essa diferença foi de $96 \%$. Resultados semelhantes foram também observados por Sakurai (1979) que encontrou incremento no ganho de peso de codornas quando se aumentou o nível de proteína da dieta de 22 para $27 \%$.

Vohra e Roudybush (1971) não observaram diferenças no ganho de peso de codornas alimentadas com dietas que variaram o nível de proteína bruta de 20 a $35 \%$.

A conversão alimentar foi linear e negativamente influenciada pelo nível de PB da dieta do nascimento ao $42^{\circ}$ dia de idade. Assim, à medida que os níveis protéicos aumentaram a conversão alimentar piorou. Weber e Reid (1967) observaram que os valores de conversão alimentar foram inversamente proporcionais de nível de proteína, ou seja, as codornas alimentadas com dietas com 15,1 e $28,8 \%$ de proteína bruta apresentaram conversão alimentar de 5,00 e 3,88, respectivamente. Sinha e Verma (1984), ao utilizarem dietas isocalóricas com 24, 26 e $28 \%$ de $\mathrm{PB}$, não encontraram diferença na eficiência alimentar.

\section{CONCLUSÕES}

A exigência de proteína bruta para o máximo ganho de peso de machos e fêmeas de codornas de corte EV1 do nascimento ao $21^{\circ}$ dia de idade é $30,1 \%$ e do nascimento ao $42^{\circ}$ dia $29,5 \%$ da dieta, o que corresponde ao consumo de $4,118 \mathrm{~g}$ e $6,096 \mathrm{~g}$ de proteína/dia/codorna.

\section{REFERÊNCIAS BIBLIOGRÁFICAS}

CORRÊA, G.S.S.; SILVA, M.A.; CORRÊA, A.B. et al. Exigência de metionina + cistina para codornas de corte em crescimento. Arq. Bras. Med. Vet. Zootec., v.58, p.414-420, 2006.

CORRÊA, G.S.S.; SILVA, M.A.; CORRÊA, A.B. et al. Exigência de proteína bruta e energia metabolizável em codornas de corte durante a fase de crescimento. Arq. Bras. Med. Vet. Zootec., v.59, p.488-494, 2007a.
CORRÊA, G.S.S.; SILVA, M.A.; CORRÊA, A.B. et al. Exigência de proteína bruta e energia metabolizável para codornas de corte EV1. Arq. Bras. Med. Vet. Zootec., v.59, p.797-804, 2007 b.

CORRÊA, G.S.S.; SILVA, M.A.; FONTES, D.O. et al. Efeito de diferentes níveis de proteína bruta sobre o rendimento de carcaça de codornas européias. Arq. Bras. Med. Vet. Zootec., v.57, p.266-271, 2005.

HYÁNKOVÁ, L.; DEDKOVÁ, L.; KNIZETVÁ, $\mathrm{H}$. et al. Responses in growth, food intake and food conversion efficiency to different dietary protein concentrations in meat-type lines of japonese quail. Br. Poult. Sci., v.38, p.564-570, 1997.

KIRKIPINAR, F.; OGUZ, I. Influence of various dietary protein levels on carcass composition in the male Japanese quail (Coturnix coturnix japonica). Br. Poult. Sci., v.36, p.605-610, 1995.

LEE, T.K.; SHIM, K.F.; TAN, E.L. Protein requirement of growth Japanese quail in the tropics. Singapore J. Prim. Ind., v.5, p.70, 1977.

LEPORE, P.D.; MARKS, H.L. Growth rate inhentance in japanese quail. 5. Protein and energy requirements of lines selected under different nutritional environment. Poult. Sci., v.50, p.1335-1341, 1971.

LESSON, S.; SUMMERS, J.D. Commercial poultry nutrition. 2.ed. Guelph, Ontario: Univ. Books, 1997. 350p.

LIMA NETO, H.R.; CORRÊA, G.S.S.; SILVA, M.A. et al. Efeito de diferentes níveis de proteína bruta e energia metabolizável sobre o desempenho de híbridos de codornas européias no período inicial de criação. In. REUNIÃO ANUAL DA SOCIEDADE BRASILEIRA DE ZOOTECNIA, 42., 2005, Goiânia. Anais... Goiânia: SBZ, 2005.

MARKS, H.L. Compensatory growth in Japanese quail following protein restriction. Poult. Sci., v.57, p.1473-1477, 1978.

MARKS, H.L. The influence of dietary protein level on body weight of Japanese quail lines selected under high and low-protein diets. Poult. Sci., v.72, p.1012-1017, 1993.

MURAKAMI, A.E. Niveis de proteina e energia em dietas de codornas japonesas (Coturnix coturnix coturnix) nas fases de crescimento $e$ postura. 1991. 92f. Tese (Doutorado) - 
Faculdade de Ciências Agrárias e Veterinárias, Universidade Estadual Paulista, Jaboticabal, SP.

NUTRIENT requirements of poultry. 9.ed. Washington: National Academy of Sciences, 1994. p.44-45.

OLIVEIRA, N.T.E.; FONSECA, J.B.; SOARES, R.T.R.N. et al. Determinação da energia metabolizável de diferentes alimentos testado em codornas japonesas fêmeas. Arq. Bras. Med. Vet. Zootec., v.59, p.210-217, 2007.

OLIVEIRA, N.T.E.; SILVA, M.A.; SOARES, R.T.R.N. et al. Exigências de proteína bruta e energia metabolizável para codornas japonesas machos criadas para a produção de carne. Arq. Bras. Med. Vet. Zootec., v.54, p.196-203, 2002 b.

OLIVEIRA, N.T.E.; SILVA, M.A.; SOARES, R.T.R.N. et al. Exigências de energia e proteína para codornas japonesas machos criadas para a produção de carne. In. REUNIÃO ANUAL DA SOCIEDADE BRASILEIRA DE ZOOTECNIA, 37., 2000, Viçosa. Anais... Viçosa: SBZ, 2000. p.89-91.

RAJINI, R.A.; NARAHARI, D. Dietary energy and protein requirements of growing japanese quails in the tropics. Indian J. Anim. Sci., v.68, p.1082-1086, 1998.
ROSTAGNO, H.S.; ALBINO, L.F.T.; DONZELE, J.L. et al. Composição de Alimentos $e$ exigências nutricionais de aves e suínos. Tabelas brasileiras para aves e suínos. Viçosa: UFV, 2000. 141p.

SAKURAI, H. Influence of levels of protein and energy of rearing diet on growth feed efficiency and egg production of japanese quail. Jpn. Poult. Sci., v.16, p.305-317, 1979.

SHRIVASTAV, A.K.; PANDA, B. A rewiew of quail nutrition research in Índia. World's Poult. Sci. J., v.55, p.73-81, 1999.

SINHA, R.R.P.; VERMA, A.K. Effect of different levels of dietary protein in japanese quail (Coturnix coturnix japonica) feeding. Indian J. Anim., v.23, p.77-80, 1984.

SISTEMA de análises estatísticas e genéticas SAEG, Versão 9.0. Viçosa: UFV, 2004.

VOHRA, P.; ROUDYBUSH, T. The effect of various levels of dietary protein on growth and egg production of Coturnix coturnix japonica. Poult. Sci., v.50, p.1081-1084, 1971.

WEBER, C.W.; REID, B.L. Protein requirements of Coturnix quail to five weeks of age. Poult. Sci., v.46, p.1190-1194, 1967. 